\title{
Deficiência como categoria do Sul Global: primeiras aproximações com a África do Sul
}

\author{
Pedro Lopes' (iD) 0000-0003-0772-4370 \\ 'Universidade de São Paulo, Programa de Pós-Graduação em Antropologia Social, \\ São Paulo, SP, Brasil. 05508-010 - ppgas@usp.br
}

\section{-2 ref}

Resumo: Neste artigo são propostas aproximações com a temática da deficiência na África do Sul, a partir da reflexão sobre o disability grant - um benefício para pessoas com deficiência que não possam trabalhar. O texto é resultado de uma pesquisa realizada a partir de interações com pesquisadores e pesquisadoras de universidades na Cidade do Cabo e região, em 2018. A produção sul-africana acerca da deficiência destaca-se no cenário internacional pela significativa história de ativismo e de elaboração de pesquisas e políticas de vanguarda. Embora ainda pouco acessada no Brasil, a tradição da África do Sul oferece referenciais teóricos e pontos de comparação etnográfica que nos ajudam a pensar a deficiência desde o Sul Global a partir de eixos mais densos que a afirmação de um ciclo de coprodução entre deficiência e pobreza, notando suas articulações constitutivas com dinâmicas raciais, espaciais e políticas.

Palavras-chove: deficiência; marcadores sociais da diferença; África do Sul; Sul Global.

Disability as a Category from the Global South: Initial Approximations with South Africa Abstract: This article offers initial approximations to the issue of disability in South Africa, based on reflections about the disability grant - a benefit for people with disabilities who cannot work. The text is a result of interactions with university researchers in Cape Town and surroundings in 2018. South African production about disability stands out on the international scene because of the significant history of activism and of research and policy elaboration. Our access to this tradition in Brazil is still limited, but it offers theoretical references and points of ethnographic comparison that help us to think about disability from the Global South through axes that may be more dense than the affirmation of a cycle of coproduction between disability and poverty, noting its constitutive articulations with racial, spatial and political dynamics. Keywords: Disability; Social Markers of Difference; South Africa; Global South.

\section{Introdução}

As filas produziram um novo e peculiar símbolo de status na África do Sul. [...] As longas horas de espera ajudaram os sul-africanos a encontrar-se uns com os outros. As pessoas dividiram seus jornais, sanduíches, guarda-chuvas [...]. Sul-africanos encontraram seus pares sul-africanos - e se deram conta do que passamos por tanto sofrimento para lhes dizer que nós compartilhamos uma humanidade comum, que a raça, a etnicidade, a cor da pele são realmente irrelevantes. [...] Um white entrava na cabine de voto carregando o peso da culpa por ter se beneficiado dos frutos da opressão e da injustiça. Mas ele saía de lá uma nova pessoa. Ele também chorava, "o peso do passado foi levantado de meus ombros, eu estou livre, transfigurado, transformado em uma nova pessoa". Agora ele podia andar de cabeça erguida e peito aberto. Os whites se deram conta de que a liberdade era de fato indivisível. Nós insistíamos em dizer, nos tempos sombrios de opressão do apartheid, que os sul-africanos whites nunca seriam verdadeiramente livres enquanto nós, os blacks, não fôssemos livres também. Muitos achavam que este era 
apenas mais um de meus slogans, irresponsável como todos os outros. Hoje, nós vivemos isso como uma realidade ${ }^{1}$ - Arcebispo Desmond TUTU (1999), em No future without forgiveness.

Uma imagem da qual o mundo se lembrará das primeiras eleições democráticas na África do Sul em 1994 é aquela de milhares de pessoas com deficiência [disabled people] em fila para as urnas de votação ao longo de todo o país, sob o quente sol africano. Elas vinham exercitar seu direito ao voto na mais difícil das circunstâncias. Vinham em cadeiras de rodas, de muletas, navegando seus caminhos com bengalas brancas [para pessoas cegas], em carrinhos de mão ou mesmo fisicamente carregadas nas costas de parentes ou amigos(as). Por que vinham? Vinham porque sabiam que a política e a prática do apartheid só serviram para compor suas experiências de discriminação, indignidade e pobreza, como um resultado da resposta da sociedade às suas diferenças [differentness]. Vinham participar em uma das experiências mais empoderadoras jamais vividas. Vinham porque tinham uma visão de melhores condições de liberdade e democracia ${ }^{2}$ - Vice-Presidente Thabo MBEKI (1998), em discurso na inauguração do Perkins Brailler Project, em Cape Town, 1998.

As epígrafes acima, que se referem a um mesmo momento, foram produzidas por duas figuras centrais para a criação da "nova" África do Sul pós-apartheid. No primeiro caso, trata-se do arcebispo anglicano e presidente da Comissão de Verdade e Reconciliação (CVR), Desmond Tutu. A segunda epígrafe é de autoria do então vice-presidente (1994-1999) e, em seguida, presidente (1999-2008) da África do Sul, Thabo Mbeki. Justaponho esses dois fragmentos de texto pois eles mobilizam exatamente a mesma imagem para construir o novo espírito nacional pósapartheid, enfatizando, em primeiro lugar, a reconciliação racial e, em segundo lugar, a inclusão de pessoas com deficiência. Em ambos os casos, a tela que se pinta é de uma África do Sul diversa e transformadora, uma "rainbow nation", a "nação arco-íris".

Em minha formação, desde a Iniciação Científica, eu estava familiarizado com a célebre descrição de Tutu, responsável pela concepção da Comissão. Na graduação, eu fizera pesquisa com Laura Moutinho sobre relações raciais, de gênero e sexualidade entre jovens na Cidade do Cabo, enquanto acompanhava diversas aulas sobre África Austral e seus múltiplos processos recentes de transformação. ${ }^{3}$ Aliás, já havíamos lido coletivamente em sala o fragmento em que o arcebispo descreve as filas da primeira eleição democrática e multirracial sul-africana. Instalada em 1995, a Comissão de Verdade e Reconciliação representou uma iniciativa singular na África do Sul e se tornou paradigma, no cenário internacional, para processos de recomposição do tecido social das nações após conflitos e violações sistêmicas de direitos humanos. A África do Sul, que vivera sob a égide do racismo de Estado na forma do apartheid, regime de profunda e violenta segregação racial, entre os anos 1950 e as primeiras eleições livres e democráticas de 1994, passou por uma ampla reconfiguração social e simbólica, chefiada por Nelson Mandela e sintetizada por sua imagem de uma "rainbow nation", a "nação arco-íris" - uma nação de várias cores, morada da diversidade afastando-se dos critérios de classificação racial e de desigualdade de gênero que arquitetaram o racismo legal. Os trabalhos da Comissão iniciaram-se em 1995 e estiveram profundamente articulados a uma série de outras transformações jurídicas e políticas, simbolicamente abertas pelas eleições que levaram Mandela à presidência da "nova" África do Sul.

No ano de 2018, realizando pesquisa na Cidade do Cabo, encontrei mais uma vez a famosa metáfora das filas para as cabines eleitorais - as primeiras filas, em décadas, nas quais "igualmente" esperavam pessoas das mais diversas cores e raças, amplamente documentadas em fotos - mobilizada por Desmond Tutu para descrever a emergência da "nação arco-íris". Desta vez, contudo, a imagem era acionada por Thabo Mbeki em um discurso em 1998. Surpreendeume, então, a concatenação produzida pelo então vice-presidente sul-africano entre deficiência, raça e nação - uma hipótese, na verdade, que estava em nossos horizontes de pesquisa no período que estive, com Laura, em Cape Town, mas que não esperávamos flagrar tão evidentemente articulada. Seguindo a pista de Mbeki, este artigo apresenta uma primeira aproximação com a temática da deficiência na África do Sul.

Em 2018, estivemos com outras pesquisadoras e pesquisadores em uma viagem de campo à Cidade do Cabo, na África do Sul, transitando entre a University of Cape Town (UCT), a Stellenbosch

\footnotetext{
' Opto aqui por não traduzir as categorias de classificação racial e mantê-las no inglês, preservando, no entanto, as regras gramaticais do português. O objetivo é chamar atenção para a diferença em relação ao sistema classificatório sul-africano, mesmo que o tema não esteja desenvolvido neste texto (nessa operação, baseio-me em textos de Laura Moutinho sobre a África do Sul, alguns dos quais eu pude coautorar, que serão mobilizados nas páginas a seguir). ${ }^{2}$ Todas as traduções para o português neste artigo são de minha autoria.

3 Integrei a pesquisa "Relations among 'race', sexuality and gender in different local and national contexts", que analisava a articulação entre raça, gênero, sexualidade e classe na trajetória de jovens em seis cidades de três países, África do Sul, Brasil e Estados Unidos. A pesquisa foi originalmente concebida por Laura Moutinho, Simone Monteiro, Cathy Cohen, Omar Ribeiro Thomaz, Rafael Diaz e Elaine Salo, e contou com uma ampla rede de colaboração, com centros de pesquisa nos três países, coordenada desde o Brasil, por Moutinho/USP, e recebeu financiamento da Fundação Ford e do CNPq.
} 
University e a University of Western Cape. ${ }^{4}$ Nesse período de pesquisa, produzi um levantamento da trajetória da categoria deficiência, mantendo dois eixos de interesse: por um lado, o da disputa política pela inclusão e a mobilização de deficiência enquanto identidade ou categoria de reivindicação e regulação; por outro lado, como noção geopolítica mobilizada desde o Sul Global e eixo analítico - neste caso, acerca das dinâmicas entre Norte e Sul, entre suas definições globais e metáforas nacionais ou locais, dialogo com o recente artigo de Anahí Guedes de MELLO e Marco Antonio GAVÉRIO (2019).

Realizei um levantamento da produção sul-africana, especialmente aquela baseada em Cape Town, operando buscas a partir da identificação de professoras e professores que trabalhavam nas universidades da região. Para tanto, segui o trabalho do corpo docente do programa de pós-graduação em Disability Studies, ou estudos sobre deficiência da UCT, bem como a produção de docentes das universidades e redes de indicação. ${ }^{5}$ O percurso que apresento aqui é uma primeira aproximação com essa bibliografia e conjunto de questões.

Importa ressaltar um aspecto do enquadramento deste esforço de pesquisa, que diz respeito a questões políticas, mas igualmente metodológicas e analíticas. Temos no Brasil um razoável e crescente acesso aos debates do campo dos Disability Studies em língua inglesa e majoritariamente produzido nos Estados Unidos e Inglaterra. Meu contato com esses trabalhos também foi assim, tanto pela leitura desse referencial, a partir da contribuição fundamental de Debora DINIZ (2007), que sistematizou em português essa tradução, quanto por oportunidades de pesquisa em território estadunidense (ver Pedro LOPES, 2014; 2019). Neste texto, apresento um olhar cruzado, para usar uma expressão de Laura MOUTINHO, Wilson TRAJANO FILHO e Andrea LOBO (2017) acerca de pesquisas antropológicas no continente africano que não seguem linhas e relações históricas (passadas e atuais) de dominação colonial, tal como foi convencional na constituição da disciplina - quando de um lado das fronteiras imperiais se produzia teoria e do outro se fazia campo etnográfico. A partir das questões com as quais temos lidado na pesquisa sobre deficiência no Brasil e de nosso repertório de leituras do Norte Global, procuro aprender com o que se tem produzido na África do Sul. Optei, assim, por privilegiar trabalhos que tenham sido produzidos em instituições sul-africanas e/ou publicados em revistas e por editoras do país - o que significa que boa parte da nacionalidade das autoras e autores também é sul-africana -, mirando no que Zethu MATEBENI (2017; in Thais TIRIBA; MOUTINHO, 2017) chamou de turning South, ou virada/virar-se para o Sul. Nessa direção, o inglês ganha outros sentidos: meu sotaque, enganos e esforços de tradução por vezes eram compartilhados por colegas, do Brasil e mesmo da África do Sul, também não nativas ou nativos da língua, e encontravam solidariedades e rebatimentos imprevistos - sobre essas trocas linguísticas na África do Sul que então eu vivia (atualmente com 12 línguas oficiais), havia escrito um artigo alguns anos atrás com Laura Moutinho (ver LOPES; MOUTINHO, 2012). Os olhares cruzados também podem envolver modos de expressar e apreender, modos de ler e escrever.

O ponto que percorro neste artigo, em relação à pesquisa realizada na Cidade do Cabo, refere-se a uma política específica, mas de grande abrangência e relevância na África do Sul contemporânea, o disability grant, um benefício para pessoas com deficiência que não possam trabalhar. Sua criação data dos anos de apartheid, mas a política é reestruturada com o fim do regime de segregação e, desde então, segue sendo um tema fundamental para a compreensão e a experiência da deficiência no país. Ler sobre o disability grant, tanto em relação a seu desenho administrativo, quanto em relação aos impasses de sua implementação, oportuniza um instigante debate sobre a própria categoria deficiência, ou disability, e suas densas articulações com a pobreza - mas também com processos de adoecimento, com relações raciais, com a geografia da distribuição de recursos. A tela que se desenha a partir da pesquisa e leitura da produção sul-africana nos ajuda a complexificar e apurar a discussão sobre deficiência também no Brasil.

\footnotetext{
${ }_{4}^{4}$ Tratou-se da pesquisa "A vizinhança nas entrelinhas: alianças e conflitos, trocas (des)iguais e cooperação entre Moçambique e África do Sul" (projeto selecionado na Chamada MCTI/CNPa n 46/2014 - Programa de Cooperação em Ciência, Tecnologia e Inovação com Países da África - PROÁFRICA), financiada pelo CNPq e coordenada por Laura Moutinho. Além de uma ampla rede de colaborações, integraram a pesquisa: Brigitte Bagnol, Esmeralda Mariano, José Ricardo Ayres, Lilia Schwarcz, Paulo Sérgio da Costa Neves, Pedro Lopes e Rita Simone Liberato, tendo sido incorporadas ao longo do processo as pesquisadoras Denise Dias Barros, Carla Braga, Solange Rocha, Gabriela Calazans, Isabel Noronha e Susan Holland-Muter. No período que estive na Cidade do Cabo, pude também contar com a companhia cotidiana e as brilhantes trocas com Paulo Neves, Thais Tiriba e Philip Leite. Este artigo se articula ao desenvolvimento de minha pesquisa de doutorado realizada no PPGAS-USP e orientada por Laura Moutinho, contando com apoio da Coordenação de Aperfeiçoamento de Pessoal de Nível Superior - Brasil (CAPES) - Código de Financiamento 001 .

${ }^{5}$ No período de pesquisa, fomos recebidos em Stellenbosch University por Shaun Viljoen, contando também com a rede de interlocuções de Laura Moutinho, especialmente as professoras da mesma instituição, Sherine van Wyk, Anthea Lesch e Colin Darch, da UCT. A partir de suas indicações e do levantamento produzido, entrei em contato com sete docentes que trabalham com deficiência, conseguindo realizar encontros pessoais com Judith McKenzie, Kharnita Mohamed, Tamara Shefer, Leslie Swartz e trocar uma série de mensagens com Brian Watermeyer. Também foram importantes conversas informais, mas muito informativas, com Bernard Dubbeld, Deborah Diedericks, Susan Holland-Muter, Solange Rocha e Pieter Odendaal. Agradeço a todas e a todos.
} 


\section{Dados quantitativos e enquadramentos nacionais: aproximações comparativas entre África do Sul e Brasil}

Este não é um artigo sistematicamente comparativo. Trata-se, no entanto, de um artigo escrito em português e, nessa medida, majoritariamente voltado a um público brasileiro. Apresento neste item um pequeno quadro comparativo nacional de questões que serão abordadas em seguida, de modo a situar a África do Sul em relação ao Brasil, que suponho ser um país mais familiar a quem lê.

Ambos os países ocupam posições geopolíticas relativamente semelhantes num cenário global e regional: compõem o BRICS, são os mais ricos de suas respectivas áreas continentais, tendo o Brasil forte protagonismo na América Latina -e, recentemente, também nas trocas com os países africanos de língua oficial portuguesa, PALOP - e a África do Sul despontando como liderança na África Austral - com relações historicamente tensas, mas sempre próximas, com vizinhos como Moçambique, Botsuana, Zimbábue, Angola e Namíbia. Ambos os países, guardadas suas diferentes histórias, também foram e são importantes destinos de imigração regional e internacional. Brasil e África do Sul, por fim, compartilham posições de protagonismo regional, igualmente dividem a perversa situação de combinar riqueza com acentuada desigualdade, havendo um aprofundamento dos altos níveis de desemprego no país africano no pós-apartheid.

Entre os anos 1980 e 1990, Brasil e África do Sul passaram por processos de democratização. No caso brasileiro, o fim da ditadura militar em 1985 foi marcado por uma série de conquistas do ponto de vista dos direitos, e a Constituição de 1988 ficou conhecida como Constituição Cidadã. Na África do Sul, os anos 1990 se abrem com a condenação pública do apartheid, que tem seu fim sacramentado pelas eleições de 1994, que levam ao poder Nelson Mandela e o parlamento responsável pela nova Constituição, saudada internacionalmente por seu caráter progressista. A partir de 1995, começam na África do Sul os trabalhos da Comissão de Verdade e Reconciliação, que se tornará outra referência global no enfrentamento de traumas políticos nacionais e da linguagem dos direitos humanos.

Diferenças entre Brasil e África do Sul agudizam-se no cenário da epidemia do HIV/Aids. Nas palavras de Gustavo Gomes da Costa SANTOS (2009), que produziu um balanço comparativo das políticas dos dois países, o Brasil costuma figurar na literatura especializada como um caso de "sucesso" na gestão da epidemia, enquanto a África do Sul é tida como um exemplo de "fracasso" (ver também MOUTINHO e Ruben MATTOS, 2009). De fato, ainda hoje a epidemia do HIV/Aids segue sendo um tema fundamental na agenda nacional sul-africana.

Em relação à deficiência, a virada dos anos 2010 dá um passo no sentido da produção de comparabilidade dos dados demográficos entre Brasil e África do Sul, ou mesmo dentro das séries históricas (por vir) de cada um desses países. Pela primeira vez em ambos os casos, os censos de 2010 do Brasil e 2011 da África do Sul adotam a metodologia do Washington Group on Disability Statistics (que segue a compreensão expressa pela Classificação Internacional de Funcionalidade, Deficiência e Saúde - CIF da Organização Mundial da Saúde, OMS, de 2001 [WHO, 2001]). Em linhas gerais, a ferramenta é organizada segundo perguntas por funcionalidades (restrições relacionadas a visão, audição, locomoção, memória etc.) e não categorias fixas de deficiência (cegueira, surdez etc.). As restrições relacionadas às funcionalidades também são escalonadas entre nenhuma, alguma e muita dificuldade (inabilidade) de realizar as atividades funcionais.

Ambos os países também compartilham algumas reservas em relação ao uso da ferramenta (como a dificuldade de incorporar pessoas com deficiência psicossocial, ou transtornos mentais na estatística - tais como esquizofrenia ou autismo). Em outras escolhas, as nações divergem: na África do Sul, crianças até 5 anos não foram contabilizadas para o censo; no Brasil, sim. No caso sul-africano, a cartilha do censo sobre deficiência (STATISTICS SOUTH AFRICA, 2014) indica que, por essas limitações e pela impossibilidade de comparação em série histórica, dada a novidade da metodologia, os resultados não devem ser tomados como representativos da prevalência ou o perfil da deficiência no país como um todo - ao contrário, a cartilha brasileira (SECRETARIA NACIONAL DE PROMOÇÃO DOS DIREITOS DA PESSOA COM DEFICIÊNCIA, 2012) apresenta seus dados em termos nacionais e sem reservas.

Em relação aos perfis populacionais agregados, por exemplo, a cartilha brasileira indica que $23,9 \%$ da população têm deficiência, mas em seguida especifica que, desse total, apenas $8,3 \%$ das pessoas têm "deficiência severa" e explica que é para esse contingente que as políticas para pessoas com deficiência estão voltadas. Na cartilha sul-africana, desde o princípio se indica que a parcela da população com deficiência é de 7,5\%, e não se nomeia pessoas com "alguma dificuldade" em uma única atividade funcional como pessoa com deficiência. Isso significa que o censo brasileiro opera um colamento entre restrição de uma determinada atividade funcional ("alguma dificuldade em enxergar") e deficiência, ao passo que o sul-africano define deficiência a partir de uma análise mais apurada das respostas, pensando a categoria deficiência mais colada à população-alvo das políticas. 
Este breve comparativo nacional sinaliza algumas das questões que desdobro nas próximas páginas - aqui abandono o exercício comparativo com o Brasil, exceto em trechos que possibilitem traçar paralelos temáticos. Do que foi apresentado, ressalto, em primeiro lugar, o engajamento do país africano com as normativas e parâmetros globais para a elaboração de dados e políticas na temática da deficiência. Esse alinhamento não é de mão única, e uma série de especialistas da África do Sul contribuiu e contribui para a construção de tais referenciais. Por outro lado, o modo de governança promovido pela Organização das Nações Unidas (ONU) e seus braços, tais como a OMS, largamente embasados na linguagem dos direitos humanos, não raro cria contradições em contato com as experiências encarnadas pelos sujeitos que essas normativas pretendem defender. Nesse sentido, o Estado nacional, os organismos internacionais e mesmo o ativismo organizado podem, por vezes, se assemelhar e dialogar mais entre si que com as vidas que procuram representar: as experiências da deficiência e de políticas públicas relacionadas têm efeitos fartamente variados.

Apresento neste artigo um percurso acerca de pesquisas sobre a política do disability grant. Ao entrevistar pesquisadoras e pesquisadores da área na África do Sul e acompanhar trabalhos que debatem tanto sua concepção quanto sua implementação, a deficiência, enquanto categoria normativa, governamental, política, identitária, subjetiva e analítica é encarnada e levanta questões que nos ajudam a adensar a compreensão de seus elos constitutivos com a desigualdade e a diferença, contribuindo para uma reflexão sobre o tema, elaborada desde o Sul.

\section{Deficiência desde a África do Sul: entre definições, direitos e desigualdades}

Uma forma de narrar a instalação de determinados regimes políticos e morais é pelo elenco de peças legislativas. Uma narrativa bastante oficial sobre o início do apartheid é descrita a partir da menção a leis que restringiram e criminalizaram os encontros inter-raciais: Prohibition of Mixed Marriages Act (1949), Immorality Act (1950), Population Registration Act (1950), Group Areas Act (1950), Reservation of Separate Amenities Act (1953) e assim por diante - sobre esse processo e para um quadro detalhado acerca da instalação do apartheid, ver Moutinho (2004a; 2004b; 2015; 2017).

Quando se descreve a instalação da "nova" África do Sul, a saída de Nelson Mandela da prisão e sua eleição aparecem como marcos fundamentais da história oficial. Para além desses marcos, seja em cartilhas do governo, seja em textos acadêmicos, também há um conjunto de peças legislativas que são referidas como pedras fundamentais da instalação do novo regime: a celebrada Constituição de 1996, Employment Equit y Act, de 1998 (e peças relacionadas) e Broad-Based Black Economic Empowerment Act, de 2003. Ambas as leis visavam à proteção e à entrada no mercado de trabalho de populações descritas como vulneráveis, tais como mulheres, blacks e pessoas com deficiência - sobre elas, ver Camilla HANSEN (2015).

No caso da deficiência, adicionam-se mais dois marcos centrais, não exatamente leis: o White Paper on the Integrated National Disability Strategy, de 1997, e o White Paper on the Rights of People with Disability, de 2015. O primeiro é descrito na cartilha sobre deficiência do Censo de 2011 como um ponto de virada na política para pessoas com deficiência a partir de um paradigma médico no enfrentamento de questões relacionadas a esse público para um paradigma social. $O$ segundo, mais recente, é uma peça que incorpora a Declaração de Direitos das Pessoas com Deficiência da ONU, de 2006 (BRASIL, 2007) - que tem peso constitucional também no Brasil desde 2008.

A história do movimento político das pessoas com deficiência na África do Sul e os efeitos de sua atuação não é o tema deste artigo, embora estivesse no escopo da pesquisa realizada na Cidade do Cabo. Numerosos trabalhos, como os de William ROWLAND (2004), David BLACK e Jacqueline de MATOS-ALA (2016) ou Colleen HOWELL, Schuaib CHALKLEN e Thomas ALBERTS (2006), descrevem a consolidação de um ativismo protagonizado por pessoas com deficiência a partir dos anos 1970. Dessa trajetória, destaco dois elementos como centrais.

Em primeiro lugar, é fundamental certa articulação entre deficiência e raça: a compreensão de que as pessoas com deficiência só seriam livres se todas as pessoas na África do Sul o fossem. Em outras palavras, o ativismo sul-africano pelos direitos das pessoas com deficiência firmou-se por meio da luta contra o apartheid e sua violência constitutiva. Por um lado, isso significava uma compreensão de que a estrutura de desigualdade e brutalidade do regime produzia deficiência em corpos racializados - fosse explicitamente, por exemplo, com a violência policial, fosse sistemicamente, com a produção, manutenção e aprofundamento da precariedade de determinados contextos de vida, por exemplo, pelo não fornecimento ou interrupção de acesso a serviços básicos como o saneamento.

Em segundo lugar, o movimento de pessoas com deficiência na África do Sul, conforme se consolidou e institucionalizou, em compasso com a luta contra o apartheid, também firmou fortes alianças com outras forças da resistência que, por sua vez, vieram a se institucionalizar mais e 
mais. Se em 1984 é fundada a Disabled People South Africa (DPSA), em 1992, a partir de alianças estabelecidas com o Congresso Nacional Africano (CNA) - organização que deixara recentemente a ilegalidade, passando a se tornar o partido pelo qual se elegeram Nelson Mandela e todos os presidentes sul-africanos desde então -, é publicado o Disability Rights Charter of South Africa (DPSA, 2013) - inspirado no histórico Freedom Charter (1955), elaborado pelo CNA e aliados. Esta declaração foi um marco fundamental tanto por seu peso nas negociações que vieram a definir as políticas para as pessoas com deficiência, quanto por seu caráter de vanguarda em relação ao que se produzia internacionalmente nessa seara. Este é apenas um elemento dessa história, que sinaliza a eficiência com que o movimento de pessoas com deficiência na África do Sul protagonizou a elaboração de dispositivos de direitos e se articulou com atores políticos, em escala nacional, fundamentais para a construção da "nova" nação - aspectos prenunciados por uma das epígrafes deste texto. Esta trajetória, contudo, não é livre de ambiguidades e o disability grant oportuniza um potente debate acerca de tais contradições.

Políticas fundamentais em relação à deficiência na África do Sul são o disability grant para pessoas com deficiência entre 18 e 59 anos que não tenham como se autossustentar; o care dependency grant, para pessoas que cuidam de crianças de até 18 anos com deficiência severa; e o grant-in-aid, para quem cuida de pessoas adultas com deficiência. Em julho de 2013, a South African Social Security Agency (SASSA) distribuía disability grants para 1,14 milhões de pessoas, 3,4\% da população economicamente ativa - a população total do país estava em 51 milhões no censo de 2011 . Foco deste texto, e o mais relevante e abrangente desses três auxílios, o disability grant representa uma pensão mensal de até 1.700 rands, ou seja, pouco menos de 130 dólares, e pode ter caráter permanente ou temporário - de seis meses a um ano, sujeito à renovação -, conforme a avaliação por especialistas. ${ }^{6}$ Além desses benefícios, a estrutura da seguridade social na África do Sul baseia-se, principalmente, no child support grant, um auxílio a pessoas responsáveis por crianças até os 18 anos, podendo ser concedido a indivíduos ou casais de baixa renda, e o old age grant, um benefício assistencial para pessoas idosas. Bernard DUBBELD (2013) realizou uma rica análise etnográfica e histórica do funcionamento do child support grant. O autor demonstrou o impacto dessa política em um cenário de profunda desigualdade e altos níveis de desemprego - produzindo uma densa reflexão sobre o difícil (des)equilíbrio entre salários e auxílios assistenciais na "nova" África do Sul -, bem como as alterações nas dinâmicas de poder, gênero, geração e parentesco que o formato de distribuição das pensões tem ocasionado no pósapartheid.

Políticas semelhantes ao disability grant são razoavelmente comuns em países do Norte Global, onde costumam estar conectadas a benefícios para pessoas com doenças crônicas e outras garantias relacionadas a seguridade social ou proteção ao desemprego. No Brasil, temos o Benefício de Prestação Continuada (BPC), que cumpre uma função semelhante à do disability grant (sobre o BPC, ver Janaína Lima Penalva da SILVA; DINIZ, 2012; PENALVA, DINIZ; Marcelo MEDEIROS, 2010; Lívia BARBOSA, DINIZ; Wederson SANTOS, 2009; bem como a etnografia de Helena Moura FIETZ, 2016). No horizonte de políticas sul-africanas, e mais amplamente na África Austral, o disability grant é considerado singular tanto por sua abrangência quanto por seu valor.

O objetivo dos grants é garantir qualidade de vida a pessoas com deficiência que, em função de suas disposições corporais, não possam acessar o mercado de trabalho. Os problemas que os grants levantam, e que procuro delinear a seguir, têm a ver tanto com seu desenho administrativo, quanto seu contexto de aplicação: não se trata de uma política formativa ou de capacitação; os grants são relativamente generosos em um contexto de muita privação e muitas vezes o único benefício a que se pode recorrer; não há outras políticas assistenciais para pessoas adultas que não tenham como se empregar - seja por adoecimento, seja por falta de oferta de vagas -; o país é atravessado por altos índices de desigualdade e desemprego. Ou seja, o debate sobre grants dá-se num contexto em que a deficiência não necessariamente opera na chave da produção de identidades culturais ou políticas ou na produção de orgulho, apesar de estar situado em um país com farta e importante história de ativismo relacionado à deficiência. Mais ainda, deficiência, aqui, em vez de ir nos evidenciando suas fronteiras em relação a classificações relacionadas a saúde e doença, a riqueza e pobreza ou a outros sistemas de diferença, mostra-se um embaralhador dessas categorias, segundo critérios historicamente localizados, no caso, especialmente relacionados à raça. Melhor dizendo, se historicamente ativismo e academia parecem concordar que a deficiência não se articula necessariamente à doença ou à pobreza, podendo, por exemplo, uma pessoa com deficiência ser rica em saúde e bens, há um consenso ao redor da noção de que pobreza (gera doença e) gera deficiência - que, por sua vez, em função da exclusão, gerará mais pobreza. O caso em questão, parece-me, oferece uma perspectiva que qualifica essa associação: a articulação entre deficiência e precariedade não é residual ou um ciclo de privações, mas efeito de políticas específicas. A desigualdade sul-africana, tão evidentemente racializada e espacializada (MOUTINHO et al.,

\footnotetext{
${ }^{6}$ Detalhes do funcionamento e abrangência das políticas estão disponíveis na página oficial da SASSA na internet.
} 
2010), dá relevo e substância a um processo que se costuma descrever em termos genéricos como um círculo vicioso.

Nessa direção, são Leslie SWARTZ e Marguerite SCHNEIDER (2006) que argumentam que os grants levantam um problema em relação à perspectiva dos direitos humanos e desenvolvimento para a deficiência por seu caráter assistencialista, em vez de formativo ou de capacitação. No entanto, ainda segundo o autor e a autora, em um cenário de altas taxas de desemprego, profundamente marcado pela epidemia do HIV, com baixo acesso à saúde, ao saneamento básico e às tecnologias assistivas, os grants tornam-se não somente uma política para pessoas com deficiência, mas uma forma de combater a pobreza - não há benefícios para pessoas adultas desempregadas no país.

A distribuição de grants para pessoas com deficiência é uma tecnologia herdada do apartheid. Gabrielle KELLY $(2013 ; 2016)$ recupera brevemente essa história. Em 1936 são criadas as primeiras pensões para pessoas whites com deficiência. Em 1946 é aprovado o Disability Grants Act, que formalizava e estruturava o esquema de pensões, estendendo-o a pessoas whites, coloureds, indians e blacks. Os valores e critérios de elegibilidade para os grants variavam enormemente entre os grupos raciais. Por exemplo, Kelly registra 60 libras por ano para whites, contra 12 libras para blacks em 1946. Essas diferenças foram se atenuando ainda durante 0 apartheid, mas é apenas com o South African Social Assistance Act de 1992 que o valor dos grants se torna universal, e não variável segundo grupo racial.

Entre o fim do apartheid e o início dos anos 2000, o sistema de grants foi marcado por sua reestruturação administrativa. O início da década de 2000 testemunhou um grande crescimento da distribuição de grants, explicado por Kelly (2013) tanto como um efeito dessa reestruturação, norteada pela ampliação do acesso a direitos, quanto exatamente do discurso nacional pelos direitos humanos e recomposição da nação, a "rainbow nation".

O redesenho da assistência social na África do Sul e o alinhamento com a linguagem dos direitos também tiveram como consequência uma incorporação da compreensão do fenômeno da deficiência que se estabelecera no campo político, do modelo social (sobre o tema do modelo social, ver, no Brasil, DINIZ, 2007; MELLO; Adriano Henrique NUERNBERG, 2012; GAVÉRIO, 2017; Pedro LOPES, 2019). ${ }^{7}$ Nesse sentido, em 2000 , a identificação da deficiência para elegibilidade ao grant passou a poder ser realizada por painéis de especialistas e não apenas médicos e médicas. Essa decisão também se embasou em uma avaliação de que a exclusividade médica na aferição da deficiência era custosa, precária em áreas mal assistidas - além da falta de profissionais, as atividades de aferição deixavam ainda menos tempo para a realização de atividades clínicas e médicos e médicas não tinham formação adequada para fazer tais avaliações. Swartz e Schneider (2006) trazem uma apresentação detalhada do funcionamento dos painéis nas províncias que os haviam adotado quando da escrita de seu artigo, bem como debatem algumas das contradições que eles levantaram. ${ }^{8}$

A definição de deficiência segundo o modelo social, como uma restrição de participação na vida social e não uma configuração corporal específica, no entanto, não se encaixa facilmente nas práticas de medição e classificação próprias ao Estado. O processo de identificação de quem tem e quem não tem deficiência, com a incorporação do modelo social, torna-se menos padronizado e de difícil administração. De fato, essa é uma das conclusões de Kelly (2016), em sua sensível tese sobre a distribuição de disability grants. Segundo a autora, um dos efeitos da incorporação desse paradigma social e da estrutura dos painéis foi a grande ampliação do número de pessoas atendidas, bem como a diversidade de configurações corporais desses sujeitos. Essa ampliação veio acompanhada de rumores, mais ou menos acompanhados por escândalos apurados acerca da má administração desses recursos ou fraudes deliberadas - sobre a lógica dos rumores, também na África do Sul, ver Moutinho (2004a; 2017) e, em outros contextos nacionais, Trajano Filho (2000) e Veena DAS (2007).

\footnotetext{
${ }^{7}$ Em linhas gerais, o modelo social da deficiência é um argumento de que a deficiência é um fenômeno de caráter social e não individual ou médico. Desenvolvido na Inglaterra nos anos 1970, tratou-se de uma reconfiguração do que se compreende por deficiência, criando-se uma distinção entre lesão, ou impedimento (impairment) e deficiência (disability), semelhante à distinção entre sexo e gênero. A lesão ou impedimento seria uma variação corporal neutra de valor, a deficiência seria a experiência de exclusão vivida por um corpo com impedimento em uma sociedade que oprime a diferença. Essa nova compreensão abre as portas para a elaboração de identidades culturais e políticas e para disputas na esfera dos direitos e não apenas da terapêutica. São incontáveis as publicações que abordam o tema do modelo social, pois, em certo sentido, ele é o mito de fundação dos estudos sobre deficiência, ou Disability Studies, e inaugura a possibilidade de se abordar o fenômeno segundo uma perspectiva sociológica.

${ }^{8}$ Esses painéis poderiam ser compostos por: especialistas em reabilitação (profissionais da enfermagem, assistência social, terapia ocupacional, psicoterapia etc.); representantes do setor da deficiência ou membros de destaque das comunidades (pessoas que ocupam posições religiosas, de chefia, magistratura); membros adicionais quando necessário (especializações médicas como psiquiatra, curandeiros ou curandeiras tradicionais). A composição do painel deve seguir três critérios: familiaridade com as temáticas da deficiência e da dependência de cuidados; familiaridade com as condições socioeconômicas da área ou comunidade em questão; o membro deve passar por treinamento no Department of Social Development. Embora o sistema de grants seja nacional do ponto de vista de seu desenho político e da origem dos recursos, sua administração é realizada pelas províncias.
} 
A ampliação da cobertura dos grants e os rumores acerca de sua manipulação levaram a um período que Kelly (2013) descreve como de "racionalização" da política, diminuindo o número de recipientes bem como o modo de definição de elegibilidade. ${ }^{9} \mathrm{Em} 2004$, a aferição da deficiência por painéis foi oficialmente abandonada e passou a ser necessário laudo médico para acessar o grant. Apesar dessa obrigatoriedade técnica, isso não necessariamente representou um afastamento total do modelo social da deficiência. Em 2001, a Organização Mundial da Saúde publicou a Classificação Internacional de Funcionalidade, Incapacidade e Saúde - CIF, fruto de um processo que se iniciara nos anos 1990, tendo contado com participação de diferentes movimentos sociais e entidades acadêmicas de diversos países. A publicação, nesse sentido, incorpora oficialmente na linguagem da OMS considerações de caráter social na definição da deficiência e ela de fato tem alguma ressonância nas práticas de distribuição de grants na África do Sul, embora não esteja literalmente incorporada à política (KELLY, 2016).

A tese de Kelly (2016) registra passos ainda mais recentes na política de grants. Interessa aqui refletir sobre o que já foi apresentado, ainda com Kelly e outras autoras e autores que se dedicam ao tema. Percorro, então, os debates sobre epilepsia e sobre a epidemia do HIV/Aids na África do Sul, na medida em que oportunizam cruzar questões sobre a elegibilidade aos grants, as fronteiras de definição entre deficiência e doença crônica, as estruturas de desigualdades socioeconômicas e desemprego e, por fim, as persistentes heranças do apartheid.

Um exemplo dessa indeterminação são as doenças crônicas com efeitos que incapacitem os sujeitos de realizarem atividades funcionais, mas que podem ser administradas por medicamentos ou terapêutica, caso se tenha acesso a eles - a deficiência como restrição à participação torna-se um estado transitório e não permanente, uma situação corporal cujas entrada e saída dependem do acesso a determinados recursos.

Hansen e Washeila SAIT (2011) apresentam alguns casos relacionados à distribuição de grants em uma vila rural na região do Eastern Cape, em um texto que dialoga, de modo complementar, com a análise de Dubbeld (2013) também sobre um contexto rural (no caso, em KwaZulu-Natal). Se Dubbeld reflete sobre os efeitos do child support grant nas dinâmicas de gênero, classe e parentesco, as autoras voltam-se para o disability grant e sua operacionalização de compreensões locais sobre deficiência, pobreza e sofrimento social. O contexto debatido por Hansen e Sait, portanto, é de extrema pobreza, em uma região herdeira do esquadrinhamento estatal do espaço promovido pelo apartheid. Em um campo atravessado por violências e desigualdades estruturais, as autoras se perguntam como discernir entre deficiência e pobreza ou exclusão social: pedindo para que as pessoas com deficiência - que recebiam ou não os grants - definissem sua experiência, ouviram respostas como: "Você é deficiente quando você não pode fazer o que quer", "Nós não podemos encontrar trabalho e não podemos trabalhar - nós temos deficiência" (p. 100). E seguem:

"As pessoas estão morrendo porque não podem se deslocar para ir a um hospital, nós queremos assistência médica, mas não há doutores/as aqui. As pessoas estão doentes e estão morrendo"; "O transporte custa dinheiro, o medicamento custa dinheiro e a distância é muito longa"; "As pessoas têm dores, convulsões, doenças, seus corpos não podem fazer o que querem"; "Nós adoecemos pela água". [...] "Por que não somos consideradas/os deficientes?" (HANSEN; SAIT, 2011 , p. 100-101).

As autoras sinalizam que a relação entre pobreza e deficiência, e a possibilidade de acessar um recurso que ameniza a pobreza contanto se tenha deficiência impulsiona as pessoas a trajetórias que buscam a medicalização como um recurso de sobrevivência - neste caso, não exatamente no sentido do cuidado de si, ou do próprio corpo, mas do autossustento, individual ou familiar.

Acompanhando quatro narrativas nas quais determinados sujeitos reivindicam para si benefícios estatais destinados a pessoas com deficiência, as autoras notam a atualização de experiências históricas acerca da exclusão, da pobreza e a relação com o Estado. As autoras destacam especialmente a desigualdade de possibilidades de identificação da deficiência por exemplo, em casos menos ostensivos que a cegueira ou a surdez, ou que podem ser revertidos com o uso de medicamentos, como a epilepsia, que atualiza linhas raciais e de gênero que persistem da geografia política do apartheid. A demanda pela produção de evidências para a aferição da deficiência - exames de raio $X$, de sangue etc. - é vivida na prática pela necessidade de deslocamento para centros urbanos ou mesmo para clínicas locais. O apartheid, no entanto, construiu-se pela interrupção de deslocamentos e não pelo seu estímulo (a esse respeito, ver, por exemplo, os relatos do artigo de Richard VERGUNST et al., 2015, "You must carry your wheelchair" ["Você deve carregar sua cadeira de rodas"]). Outra observação de Hansen e Sait (2011) é o

\footnotetext{
${ }^{9}$ O tema da corrupção tomou a agenda pública sul-africana nos últimos anos da gestão de Jacob Zuma. Em fevereiro de 2018, enquanto estávamos em Cape Town, o presidente renunciou, já sem apoio do CNA. Cyril Ramaphosa, também do CNA, assumiu a presidência (e foi reeleito em 2019). As análises desse processo são variadas e nos ocuparam por todas as semanas de trabalho na África do Sul.
} 
compartilhamento vital de benefícios estatais por famílias inteiras e não apenas os sujeitos específicos que têm deficiência, que coloca em outros termos o que em países do Norte Global muitas vezes aparece como uma acusação da fragilidade de certas políticas - familiares que encontram brechas para expropriarem as pessoas com deficiência de seu dinheiro. As autoras questionam, então: nesse contexto, não faria mais sentido que o grant fosse concedido a famílias que a indivíduos? No entanto, isso não fere o paradigma dos direitos humanos, o compromisso com o empoderamento e uma certa compreensão de autonomia e vida independente - valores históricos da luta das pessoas com deficiência?

Um dos casos debatido por Hansen e Sait (2011) é de uma pessoa com epilepsia, ou, segundo os termos localmente mobilizados, alguém "having fits", ou que "tem ataques". Os casos de epilepsia levantam controvérsias em relação à concessão de grants tanto em função do vasto leque de causas para esses quadros, quanto em função das significativas chances de administração e mesmo interrupção de episódios convulsivos por meio da adesão a tratamentos medicamentosos. Uma causa relativamente comum para quadros epilépticos é a cisticercose, uma doença associada a condições precárias de saneamento básico. As autoras retomam pesquisas que indicam que o Eastern Cape é uma região particularmente endêmica dessa condição, que segue com baixo controle devido à falta de ferramentas diagnósticas e intervenções apropriadas. Ou seja, mais uma vez, há uma significativa relação entre "having fits" e um tipo de pobreza produzido pelo sistema de segregação racial, que desenhou legal e concretamente as fronteiras de raça no espaço geográfico.

Julia SEGAR (1994), em uma pesquisa conduzida ainda nos anos 1990, faz observações valiosas acerca da epilepsia que contribuem para nos conduzir em seguida para o tema do HIV. Ela registra que, na produção de evidências para um diagnóstico de epilepsia, a presença de uma pessoa que tenha testemunhado os episódios convulsivos é fundamental, já que um exame clínico raramente pode ser conclusivo. Os custos de deslocamento dessa testemunha para os centros de saúde representam mais um fardo econômico, mas é a saída encontrada, já que os testes que seriam necessários para um diagnóstico definitivo, como eletroencefalograma, requerem equipamentos caríssimos e disponíveis apenas nos hospitais das grandes cidades. Outro impasse encontrado no tratamento da epilepsia é a diferença linguística entre profissionais da saúde e pacientes: muitas vezes as consultas são mediadas por intérpretes e várias informações se perdem ou reconfiguram no trânsito entre as vozes do atendimento clínico.

Nesse contexto, a adesão a tratamentos entra em um jogo contraditório com a manutenção do disability grant: a reversão de um quadro epiléptico pode significar a perda do grant, uma vez que, sem episódios convulsivos, o corpo dos sujeitos pode não mais desabilitá-los à realização de funções laborais (SEGAR, 1994). Conforme assinalamos, o disability grant é destinado a pessoas que não conseguem trabalhar: arranjar um emprego significa perder um grant permanente ou não conseguir renovar um temporário.

A epidemia do HIV/Aids na África do Sul levanta questões semelhantes em relação à política de grants para pessoas com deficiência, mas também nos remete a um debate mais amplo sobre a história do país. Nos anos 2000, a África do Sul já se consolidara como um gravíssimo caso mundial da epidemia: a cada 10 pessoas vivendo com HIV no mundo, uma era sul-africana, e a cada 10 pessoas sul-africanas, uma viveria com HIV. Entre 1990 e 2000, a expectativa de vida ao nascer no país diminuíra dos 60 aos 40 anos. Nas palavras de Didier FASSIN (2007), "Livre da violência do apartheid, a sociedade sul-africana tornara-se vítima do desastre da Aids" (p. 3).

Para abordar a temática do HIV/Aids na África do Sul recorro ao trabalho de Fassin (2007), When Bodies Remember, pelo interesse no modo como este autor francês enquadra as controvérsias acerca da epidemia, articulando-as à história nacional. Fassin analisa essa história a partir de um quadro da estrutura ideológica da sociedade sul-africana pós-apartheid, que articula três elementos (p.70-74): (1) Identidade nacional - o ambíguo e delicado esforço pós-apartheid por afastar a identidade nacional de termos raciais, o projeto de "rainbow nation" de Nelson Mandela. (2) Raça - o vírus do HIV pode infectar qualquer pessoa, independentemente de seu corpo, sua posição de classe, raça, gênero ou sexualidade, mas, na África do Sul, a proliferação da epidemia seguiu as linhas raciais desenhadas pelo apartheid. (3) Teoria da conspiração - a construção ideológica e política do apartheid fundamentou-se em práticas discursivas conspiratórias, tanto em termos dos rumores relacionados a supostos perigos à nação, internos e externos, quanto pela própria ilegibilidade do sistema e controle dos meios de comunicação e produção ideológica.

Ajustando esses três elementos para o debate sobre deficiência, os primeiros dois termos já foram razoavelmente explorados neste artigo. No primeiro caso, observamos como as políticas para pessoas com deficiência, tanto desde o movimento social, quanto desde o Estado, também se constituíram de certo esforço universalista, da ênfase nas políticas transversais, da linguagem dos direitos humanos e do pendor redistributivo e promotor da inclusão que caracterizam o projeto de uma "nação arco-íris". No segundo caso, observamos como a distribuição e a experiência da deficiência atualizam desigualdades e fronteiras raciais construídas duramente pelos longos e 
violentos anos de apartheid. Em relação ao terceiro ponto de Fassin, o elemento conspiratório, a discussão sobre os disability grants nos assinala ambiguidades interessantes. As polêmicas em torno aos grants colocam em fricção o projeto de inclusão "arco-íris" e as atualizações do racismo legal vividas cotidianamente, o que se expressa tanto na linguagem dos rumores ou suspeições, quanto pela frustração vivida com o fim do apartheid e a espera por um país menos desigual.

Caminhando para o fim de sua análise, Fassin (2007, p. 224-227) faz uma pequena reflexão sobre as possibilidades de agência experimentadas pelas pessoas, especialmente blacks vivendo com HIV na África do Sul, e submetidas a tantos constrangimentos e opressões estruturais. Duas histórias apresentadas em sua etnografia são retomadas nesse ponto. Em ambos os casos, é a transformação na vida dos sujeitos ocasionada pela infecção pelo HIV que reorienta suas trajetórias e oferece-lhes possibilidades de ação antes inacessíveis: em um caso pelo engajamento político, no outro pelo recebimento do disability grant. Fassin (2007) arremata: "Doença também é um recurso social" (p. 225).

Nicoli NATTRASS (2012) oferece uma dura e ampla crítica à perspectiva de Fassin, especialmente apontando que a "compreensiva" perspectiva do autor ao negacionismo de Thabo Mbeki produz uma imagem estereotipada da suposta "resposta africana" aos discursos biomédicos "ocidentais", dando a impressão de que Mbeki expressaria uma compreensão amplamente difundida da epidemia do HIV/Aids. Ao contrário, a autora ressalta que o presidente estava politicamente isolado em seu posicionamento, inclusive em relação a colegas de partido. Além disso, ela argumenta que o problema da posição negacionista de Mbeki não estava em sua lógica, que rivalizava com a corrente ortodoxa (que entendia o HIV enquanto causa da Aids, a ser combatido segundo uma abordagem medicamentosa e comportamental). Nattrass reconhece que a lógica argumentativa de Mbeki, de associar a epidemia da Aids à pobreza, estava na verdade em linha com a compreensão patogênica ortodoxa da infecção à época. A questão, segundo a autora, é que Thabo Mbeki argumentava em favor de intervenções que combatessem a pobreza e promovessem o desenvolvimento econômico em vez e à custa direta do tratamento por antirretrovirais e da prevenção da transmissão vertical do HIV.

A análise de Fassin, no entanto, nos ajuda a pensar sobre agência relacionada ao disability grant, não necessariamente definindo a experiência do adoecimento ou da doença em termos de um recurso social. A própria Nattrass (2006) identifica a ambiguidade da política de grants no caso do HIV, ou, mais especificamente, no adoecimento por Aids: pessoas que vivem sintomas debilitantes da Aids se qualificam para os grants, mas, caso sua saúde melhore, perdem-no. Dadas as altas taxas de desemprego na África do Sul, o quadro que se desenha é, nos termos da autora, um trade-off, ou troca, entre saúde e renda. Sem dúvida, é possível notar aqui uma forma de agência. No entanto, essa agência não caminha exatamente na direção da possibilidade de fazer frente a estruturas de desigualdade e opressão, como argumentava Fassin, mas habitá-las de modo negociado.

Nessa discussão, Swartz é uma figura-chave no trabalho sobre deficiência, tendo se dedicado também a pensar as articulações entre deficiência e HIV. Junto a Marguerite Schneider e Poul ROHLEDER, Swartz (2006) também assinala a perversa ambiguidade da concessão de grants temporários para pessoas adoecidas por Aids em situação de pobreza: por exemplo, uma pessoa com HIV que esteja inapta ao trabalho recebe o grant, por meio do qual tem como pagar os custos do tratamento com antirretrovirais (mesmo quando os medicamentos estão disponíveis com gratuidade, a adesão ao tratamento requer uma disciplina corporal e alimentar e um deslocamento frequente a centros de saúde, atividades cuja manutenção é custosa) ou muitas vezes garantir o suporte financeiro de uma família inteira. Quando ela se torna apta a trabalhar, é possível que não consiga uma colocação em função das altas taxas de desemprego. No entanto, por ter recobrado suas capacidades físicas de modo a se tornar apta a trabalhar, a pessoa perde o grant. Trata-se precisamente do trade-off descrito por Nattrass.

Além dessa associação, Swartz, Schneider e Rohleder (2006) fazem reflexões interessantes sobre as articulações entre deficiência e HIV/Aids, partindo da constatação de que, apesar de as pessoas com deficiência estarem entre os grupos mais vulneráveis à infecção por HIV, quase nenhuma atenção lhes é dedicada na África do Sul - o mesmo vale para outros contextos, inclusive o brasileiro (ver, por exemplo, Nádia MEINERZ, 2010; Julian SIMÕES, 2014) - pelas campanhas de prevenção e promoção da saúde, em função de seu estereótipo como pessoas sem sexualidade. A reflexão dos autores e da autora sobre estigmas segue, e apontam que pessoas com deficiência compartilham com aquelas vivendo com HIV estereótipos relacionados a imagens de perigo, poluição, corrupção, enfim, que são responsáveis pelas suas configurações corporais, entendidas como indesejáveis. No entanto, assinalam Swartz, Schneider e Rohleder, esses estigmas não são equivalentes nem operam em uma mesma direção: eles se articulam. Os esforços por retirar o estigma das pessoas vivendo com HIV redundaram muitas vezes capacitistas: 10 "nós somos normais"

\footnotetext{
${ }^{10} \mathrm{Em}$ linhas gerais, capacitismo é o termo pelo qual se tem nomeado a discriminação e a violência contra pessoas
} com deficiência, uma categoria semelhante a racismo, machismo, homofobia, transfobia etc. 
(sobre o termo, ver MELLO, 2016; Adriana DIAS, 2013). O artigo rememora um discurso realizado pela criança Nkosi Johnson na Conferência Internacional sobre Aids em Durban no ano de 2000:

Eu quero que as pessoas tenham conhecimento sobre Aids, sejam cuidadosas e respeitosas com a Aids. Você não pode pegar Aids se tocar, abraçar, beijar ou dar as mãos com uma pessoa infectada. Cuide de nós, aceite-nos - somos todos seres humanos. Nós somos normais. Nós temos mãos. Nós temos pés. Nós podemos andar, podemos falar, nós temos necessidades como qualquer outra pessoa. Não tenha medo de nós. Somos todos iguais! (Nkosi Johnson, 2000, apud SWARTZ et al., 2006, p. 110).

O discurso do pequeno Nkosi Johnson é sensível e corajoso. No entanto, ele nos aponta para um questionamento acerca das contradições vividas na luta pela inclusão de pessoas com deficiência e de pessoas vivendo com HIV - para que se produza um efeito de normalidade na descrição de pessoas com HIV, a estratégia escolhida no caso foi afastá-las dos estigmas de incapacidade e dependência associados a pessoas com deficiência.

Em outro artigo também de Swartz e Rohleder, agora em coautoria com Arne EIDE e Hayley MacGREGOR (2009), questões semelhantes são abordadas por outras perspectivas. Se o texto anterior debatia HIV/Aids em uma coletânea sobre deficiência, neste caso temos um artigo que debate deficiência em uma coletânea sobre a epidemia do HIV/Aids - em ambos os casos, coletâneas dedicadas ao cenário da África do Sul. Neste caso, os autores e autoras sinalizam que o ativismo de pessoas com deficiência costuma desenhar uma fronteira entre deficiências físicas ou visíveis e o status soropositivo para reivindicar uma hierarquia de direito em relação à distribuição de grants - neste caso, as fronteiras entre deficiência e Aids se assemelhariam às fronteiras entre deficiência e transtornos mentais. No entanto argumenta-se no artigo, que a infecção por HIV pode ocasionar experiências de adoecimento com impactos debilitantes mentais e físicos: onde estaria, perguntam-se Swartz e colegas - à revelia tanto do ativismo das pessoas com deficiência, quanto das pessoas vivendo com HIV, a fronteira entre Aids e deficiência na vida dos sujeitos?

Com essa pergunta encerro este percurso inicial por debates contemporâneos que identifiquei no mapeamento da produção sobre deficiência na África do Sul, com foco na região do Cabo. A política dos disability grants levanta problemas na definição do que seja a deficiência - ou, talvez, como se vive a deficiência. Ao mesmo tempo, trata-se de uma política fundamental para o combate à pobreza em um contexto muito desigual e, mais que isso, uma política com um alcance significativo. A epidemia do HIV/Aids e o modo como ela se instalou na África do Sul pósapartheid colocam em evidência que a definição da deficiência não somente é uma questão local: ela se articula com categorias classificatórias e experiências de exclusão e inclusão em termos de raça, classe e saúde/doença de modos tão intrincados que podem nos colocar desafios acerca da identificação de suas fronteiras constitutivas.

\section{Deficiência desde o Sul: articulações para além da pobreza}

Concluo estas primeiras aproximações a partir da pesquisa realizada na África do Sul com um comentário acerca do enquadramento da noção de deficiência que os trabalhos parecem apontar. Conforme argumentei, no Brasil, o acesso que temos tido ao debate sobre deficiência na antropologia e sociologia é bastante referido ao Norte Global. Nesses países, a descrição da deficiência costuma ser como uma condição corpórea congênita que se desdobraria na produção de identidades. Nessa literatura, no entanto, a abordagem da deficiência segundo uma lógica de reconhecimento e não marginalização viria historicamente com a experiência dos veteranos de guerra, na primeira metade do século XX. Em seguida, no desenrolar do século, guerra e deficiência trilham caminhos separados e, se de um lado se fala em trauma e reparação, do outro se fala em orgulho e inclusão. Embora tais termos não sejam antitéticos, acabaram por se afastar: a linguagem do trauma e da dor foi crescentemente repelida pela discussão sobre deficiência, conforme esta procurou se articular em orgulho, pela afirmação da diversidade corporal e rejeição de uma narrativa em termos de "falta" ou "desajuste". É apenas em anos mais recentes, desde a virada para este século, que autoras e autores dos Disability Studies, ou estudos sobre deficiência, voltam a tematizar a dor e a rearticular deficiência a doenças crônicas ou ao efeito da guerra ou da pobreza (p. ex.: Susan WENDELL, 2013).

Nesse debate, o Sul Global aparece como um campo no qual se pode observar a coprodução entre deficiência e pobreza - mas não há muitos qualificativos para esse elo. A densa compreensão acerca do fenômeno da deficiência a que tive acesso na África do Sul ajuda a complexificar esse cenário. Ela nos convida a pensar a deficiência no Sul Global não apenas na chave congênita/ identitária, mas como um efeito de políticas de Estado que sistematicamente incapacitaram e incapacitam determinados corpos, seja pela precariedade de condições básicas de saúde, alimentação e saneamento, seja pela produção de uma geografia política desigual e segregadora. Além disso, ela nos permite pensar a deficiência como uma linguagem a partir da qual se pode nomear a pobreza, a desigualdade racial (econômica e espacial) e as condições de saúde e 
doença, e pleitear direitos frente ao Estado - de modo semelhante ao que se desenvolveu no combate à epidemia do HIV/Aids. Em outras palavras, quando pensamos em deficiência e pobreza, não se trata apenas de um círculo vicioso de precariedades e privações, mas trajetórias históricas que se produzem na articulação entre outros eixos de diferença, como raça, classe e saúde, bem como constroem a nação ao mesmo tempo que se constroem em relação a ela.

Em um país atravessado por desigualdades profundas, cultivadas pelos duros anos do apartheid, os esforços por "verdade e reconciliação" têm de lidar não somente com o legado do sistema racista, mas igualmente com seus próprios anseios e estratégias na construção da igualdade - nas quais paradigmas (neo)liberais, que sustentaram a nascente democracia, ocupam uma posição ambígua, entre causa e efeito do que se desenvolve no país. A partir da África do Sul, a Comissão de Verdade e Reconciliação de fato tornou-se uma estrela a ser seguida pela comunidade internacional; a legislação alinhada com os direitos humanos segue sendo vanguarda tanto no contexto regional quanto mundial; o disability grant é uma política ampla e sem igual na África Austral e mesmo outras regiões do Sul Global; por fim, as conquistas do movimento sul-africano de pessoas com deficiência são notáveis e tornaram-se referência: a máxima "nothing about us without us", ou "nada sobre a gente sem a gente", foi elaborada pelo ativismo sulafricano, mas se tornou um lema global de movimentos de pessoas com deficiência, para não dizer de minorias em geral (sobre a expressão em sua repercussão no Brasil, ver os textos de Romeu SASSAKI, 2007a; 2007b ${ }^{11}$ ).

Neste artigo, procurei delinear primeiras aproximações com a África do Sul na temática da deficiência. A história que aprendemos com autoras e autores do outro lado do Atlântico Sul nos mostra que a deficiência, como categoria do Sul Global, não produz apenas pobreza, mas produz resistência, articulação política e reflexão teórica.

\section{Referências}

BARBOSA, Lívia; DINIZ, Debora; SANTOS, Wederson. "Diversidade corporal e perícia médica: novos contornos da deficiência para o Benefício de Prestação Continuada". Revista Textos \& Contextos, Porto Alegre, v. 8, n. 2, p. 377-390, jul./dez. 2009.

BLACK, David R.; MATOS-ALA, Jacqueline de. "Building a more inclusive South Africa: progress and pitfalls in disability rights and inclusion". Third World Thematics: A TWQ Journal, v. 1, n. 3, p. 335$352,2016$.

BRASIL. Convenção sobre os direitos das pessoas com deficiência. UNESCO/Secretaria Especial de Direitos Humanos/Coordenadoria Nacional para a Integração da Pessoa Portadora de Deficiência, 2007. Disponível em http://portal.mec.gov.br/component/docman/?task=doc_download\&gid=424 \&ltemid $=$.

CONGRESS of the People at Kliptown. The Freedom Charter. Johannesburg, 25-26/06/1955. Disponível em https://disa.ukzn.ac.za/sites/default/files/DC\%20Metadata\%20Files/Gandhi-Luthuli\%20Documen tation\%20Centre/TheFreedomCharter1955/TheFreedomCharter1955.pdf.

DAS, Veena. Life and Words: Violence and the descent into the ordinary. Berkeley/Los Angeles: University of California Press, 2007.

DIAS, Adriana. Por uma genealogia do capacitismo: da eugenia estatal a narrativa capacitista social. I SIMPÓSIO INTERNACIONAL DE ESTUDOS SOBRE A DEFICIÊNCIA. SEDPCD/Diversitas/USP Legal, São Paulo, Anais..., 2013.

DINIZ, Debora. O que é deficiência? São Paulo: Editora Brasiliense, 2007.

DPSA. Disability Rights Charter of South Africa, 2013. Disponível em https://www.medbox.org/zadisability/disability-rights-charter-of-south-africa/preview?q=.

DUBBELD, Bernard. "How social security becomes social insecurity: Unsettled households, crisis talk and the value of grants in a KwaZulu-Natal village". Acta Juridica, n. 1, p. 197-217, jan. 2013.

FASSIN, Didier. When Bodies Remember: Experience and Politics of AIDS in South Africa. Berkeley: University of California Press, 2007.

FIETZ, Helena Moura. Deficiência e práticas de cuidado: uma etnografia sobre "problemas de cabeça" em um bairro popular. 2016. Dissertação (Mestrado em Antropologia Social) - Universidade Federal do Rio Grande do Sul, Porto Alegre, 2016.

\footnotetext{
${ }^{11}$ Agradeço a Anahí Guedes de Mello por me apresentar essa referência.
} 
GAVÉRIO, Marco Antonio. "Nada sobre nós, sem nossos corpos! O local do corpo deficiente nos Disability Studies". Revista Argumentos, Montes Claros, v. 14, n. 1, p. 95-117, 2017.

HANSEN, Camilla. "Ability in disability enacted in the National Parliament of South Africa". Scandinavian Journal of Disability Research, v. 17, n. 3, p. 258-271, 2015.

HANSEN, Camilla; SAIT, Washeila. "We too are disabled": disability grants and poverty politics in rural South Africa. In: EIDE, Arne H.; INGSTAD, Benedicte (Orgs.). Disability and Poverty: A Global Challenge. Portland: The Policy Press, 2011. p. 93-11.

HOWELL, Colleen; CHALKLEN, Schuaib; ALBERTS, Thomas. "A history of the disability rights movement in South Africa". In: WATERMEYER, Brian et al. (Orgs.). Disability and Social Change: A South African Agenda. Cidade do Cabo: HSRC Press, 2006. p. 46-84.

KELLY, Gabrielle. Regulating access to the disability grant in South Africa, 1990-2013. Cidade do Cabo: Centre for Social Science Research, University of Cape Town, 2013.

KELLY, Gabrielle. Conceptions of Disability and Desert in the South African Welfare State: The Case of Disability Grant Assessment. 2016. Tese (Doutorado) - University of Cape Town, Cape Town, 2016.

LOPES, Pedro; MOUTINHO, Laura. "Uma Nação de Onze Línguas? Diversidade social e linguística nas novas configurações de poder na África do Sul”. Tomo, UFS, v. 20, p. 27-57, 2012.

LOPES, Pedro. Negociando Deficiências: identidades e subjetividades entre pessoas com "deficiência intelectual". 2014. Dissertação (Mestrado em Antropologia Social) - Universidade de São Paulo, São Paulo, 2014.

LOPES, Pedro. "Deficiência como categoria analítica: Trânsitos entre ser, estar e se tornar". Anuário Antropológico, n. I, p. 67-91, 2019.

MATEBENI, Zethu. "Perspectivas do Sul sobre relações de gênero e sexualidades: uma intervenção queer". Revista de Antropologia, São Paulo, v. 60, n. 3, p. 26-44, dez. 2017.

MBEKI, Thabo. Speech by Deputy President Thabo Mbeki at the official opening of the Perkins Brailler Project, 16/01/1998. Disponível em https://www.mbeki.org/2016/06/06/speech-at-the-officialopening-of-the-perkins-brailler-project-199801 16/. Acesso em 10/06/2018.

MEINERZ, Nádia Elisa. "Corpo e outras (de)limitações sexuais. Uma análise antropológica da revista Sexuality and Disability entre os anos de 1996 e 2006". Revista Brasileira de Ciências Sociais, v. 25, n. 72, p. 117-178, fev. 2010.

MELLO, Anahí Guedes de. "Deficiência, incapacidade e vulnerabilidade: do capacitismo ou a preeminência capacitista e biomédica do Comitê de Ética em Pesquisa da UFSC". Ciência \& Saúde Coletiva, v. 21, n. 10, p. 3265-3276, 2016.

MELLO, Anahí Guedes de; NUERNBERG, Adriano Henrique. "Gênero e deficiência: interseções e perspectivas". Revista Estudos Feministas, v. 20, n. 3, p. 635-655, 2012.

MELLO, Anahí Guedes de; GAVÉRIO, Marco Antonio. "Facts of cripness to the Brazilian: Dialogues with Avatar, the film". Anuário Antropológico, v. 44, n. 1, p. 43-65, jun. 2019.

MOUTINHO, Laura. Razão, "Cor" e Desejo: uma análise comparativa sobre relacionamentos afetivosexuais "inter-raciais" no Brasil e na África do Sul. São Paulo: EDUNESP, 2004a.

MOUTINHO, Laura. "Condenados pelo desejo? Razões de estado na África do Sul". Revista Brasileira de Ciências Sociais, v. 19, n. 56, p. 95-112, 2004b.

MOUTINHO, Laura. "The other side? Das implicações morais de certos horizontes imaginativos na África do Sul”. Anuário Antropológico, Brasília, UnB, v. 40, n. 2, p. 77-97, 2015.

MOUTINHO, Laura. Des braves gens qu'ils aiment de détester ensemble. 2017. Tese (Livre Docência) - Universidade de São Paulo, São Paulo, 2017.

MOUTINHO, Laura; LOPES, Pedro; ZAMBONI, Marcio; RIBAS, Mario; SALO, Elaine. "Retóricas Ambivalentes: ressentimentos e negociações em contextos de sociabilidade juvenil na Cidade do Cabo (África do Sul)". Cadernos Pagu, n. 35, p. 139-176, 2010. 
MOUTINHO, Laura; MATOS, Ruben (Orgs.). "Dossiê - A prevenção do HIV/Aids em diferentes contextos culturais e nacionais". Physis, v. 19, n. 2, 2009.

MOUTINHO, Laura; TRAJANO FILHO, Wilson; LOBO, Andréa. "Dossiê Olhares Cruzados para a África: Trânsitos e mediações - Algumas reflexões". Revista de Antropologia, São Paulo, v. 60, n. 3, p. 7-25, dec. 2017.

NATTRASS, Nicoli. "Trading off Income and Health?: AIDS and the Disability Grant in South Africa". Journal of Social Policy, n. 35, p. 3-19, 2006.

NATTRASS, Nicoli. The AIDS Conspiracy: Science Fights Back. Nova York: Columbia University Press, 2012.

PENALVA, Janaína; DINIZ, Debora; MEDEIROS, Marcelo. "O Benefício de Prestação Continuada no Supremo Tribunal Federal”. Revista Sociedade e Estado, v. 25, n. 1, p. 53-70, jan./abr. 2010.

ROHLEDER, Poul; SWARTZ, Leslie; EIDE, Arne Henning; MacGREGOR, Hayley. "HIV/AIDS and Persons with Disabilities". In: ROHLEDER, Poul et al. (Orgs.). HIVIAids in South Africa 25 Years On: Psychosocial Perspectives. Nova York e Londres: Springer, 2009. p. 289-304.

ROWLAND, William. Nothing about Us without US: Inside the Disability Rights Movement of South Africa. Cidade do Cabo: Unisa Press, 2004.

SANTOS, Gustavo Gomes da Costa. "Aids, Política e Sexualidade: refletindo sobre as respostas governamentais à Aids na África do Sul e no Brasil". Physis, v. 19, n. 2, p. 283-300, 2009.

SASSA. Social Grants. South African Social Security Agency, África do Sul. Disponível em https:// www.sassa.gov.za/. Acesso em 22/1 1/2018.

SASSAKI, Romeu Kazumi. "Nada sobre nós, sem nós: Da integração à inclusão - Parte 1". Revista Nacional de Reabilitação, ano X, n. 57, p. 8-16, jul./ago. 2007a.

SASSAKI, Romeu Kazumi. "Nada sobre nós, sem nós: Da integração à inclusão - Parte 2". Revista Nacional de Reabilitação, ano X, n. 58, p. 20-30, set./out. 2007b.

SECRETARIA NACIONAL DE PROMOÇÃO DOS DIREITOS DA PESSOA COM DEFICIÊNCIA. Cartilha do Censo 2010 - Pessoas com Deficiência. Texto de Luiza Maria Borges Oliveira. Brasília: Secretaria de Direitos Humanos da Presidência da República (SDH/PR)/Secretaria Nacional de Promoção dos Direitos da Pessoa com Deficiência (SNPD), 2012.

SEGAR, Julia. "Negotiating Illness: Disability Grants and the Treatment of Epilepsy". Medical Anthropology Quarterly, v. 8, n. 3, p. 282-98, 1994.

SILVA, Janaína Lima Penalva da; DINIZ, Debora. "Mínimo social e igualdade: deficiência, perícia e benefício assistencial na LOAS". Revista Katálysis, Florianópolis, v. 15, n. 2, p. 262-269, jul./dez. 2012.

SIMÕES, Julian. Assexuados, libidinosos ou um paradoxo sexual? Gênero e sexualidade em pessoas com deficiência intelectual. 2014. Dissertação (Mestrado em Antropologia Social) - Unicamp, Campinas, 2014.

STATISTICS SOUTH AFRICA. Census 2011: Profile of Persons with Disabilities in South Africa. Pretoria: Statistics South Africa, 2014.

SWARTZ, Leslie; SCHNEIDER, Marguerite. "Tough choices: disability and social security in South Africa". In: WATERMEYER, Brian et al. (Orgs.). Disability and Social Change: A South African Agenda. Cidade do Cabo: HSRC Press, 2006. p. 234-244.

SWARTZ, Leslie; SCHNEIDER, Marguerite; ROHLEDER, Poul. "HIV/AIDS and disability: new challenges". In: WATERMEYER, Brian et al. (Orgs.). Disability and Social Change: A South African Agenda. Cidade do Cabo: HSRC Press, 2006. p. 108-115.

TIRIBA, Thais; MOUTINHO, Laura. “'Olhares compartilhados': (des)continuidades, interseccionalidade e desafios da relação Sul-Sul. Entrevista com Zethu Matebeni”. Revista de Antropologia, São Paulo, v. 60, n. 3, p. 181-185, dez. 2017.

TRAJANO FILHO, Wilson. "Outros rumores de identidade na Guiné-Bissau". Série Antropologia, Brasília, DAN-UnB, n. 279, 2000. 
TUTU, Desmond. No future Without Forgiveness. Nova York: Doubedlay, 1999.

VERGUNST, Richard; SWARTZ, Leslie; MJI, Gubela; MacLACHLAN, Malcolm; MANNAN, Hasheem. "You must carry your wheelchair" - barriers to accessing healthcare in a South African rural area. Global Health Action, v. 8, n. 1, p. 1-8, 2015.

WENDELL, Susan. "Unhealthy Disabled: Treating Chronic Illnesses as Disabilities". In: DAVIS, Lennard (Org.). The Disability Studies Reader. 4. ed. Nova York/Oxon: Routledge, 2013. p. 161-176.

WHO. World Health Organization. The International Classification of Functioning, Disability and Health. Geneva: ICF, 2001. Disponível em http://www.who.int/classifications/icf/en/.

Pedro Lopes (pedro.lopes@usp.br) é mestre e doutorando em Antropologia Social pela Universidade de São Paulo. No mestrado, realizou estágio de pesquisa no exterior, na Universidade de Princeton (Estados Unidos), e no doutorado na Universidade de Stellenbosch (África do Sul). É membro do Núcleo de Estudos sobre Marcadores Sociais da Diferença (Numas-USP) e professor da Escola da Cidade - Faculdade de Arquitetura e Urbanismo.

\section{COMO CITAR ESSE ARTIGO DE ACORDO COM AS NORMAS DA REVISTA}

LOPES, Pedro. "Deficiência como categoria do Sul Global: primeiras aproximações com a África do Sul”. Revista Estudos Feministas, Florianópolis, v. 27, n. 3, e66923, 2019.

CONTRIBUIÇÃO DE AUTORIA

Não se aplica.

\section{FINANCIAMENTO}

Edital PROÁFRICA CNPq: "A vizinhança nas entrelinhas: alianças e conflitos, trocas (des)iguais e cooperação entre Moçambique e África do Sul" (projeto selecionado na Chamada MCTI/CNPq n 46/2014 - Programa de Cooperação em Ciência, Tecnologia e Inovação com Países da África PROÁFRICA).

Bolsa de doutorado Capes: Coordenação de Aperfeiçoamento de Pessoal de Nível Superior Brasil (CAPES) - Código de Financiamento 001.

\section{CONSENTIMENTO DE USO DE IMAGEM}

Não se aplica.

APROVAÇÃO DE COMITÊ DE ÉTICA EM PESQUISA

Não se aplica.

\section{CONFLITO DE INTERESSES}

Não se aplica.

\section{LICENÇA DE USO}

Este artigo está licenciado sob a Licença Creative Commons CC-BY International. Com essa licença você pode compartilhar, adaptar, criar para qualquer fim, desde que atribua a autoria da obra.

\section{HISTÓRICO}

Recebido em 06/08/2019.

Aprovado em 16/08/2019. 